\title{
COVID-19 AND THE RENIN ANGIOTENSIN SYSTEM: IMPLICATIONS FOR THE OLDER ADULTS
}

\begin{abstract}
G. BAHAT ${ }^{1}$
1. Istanbul University, Istanbul Medical Faculty, Department of Internal Medicine, Division of Geriatrics, Istanbul, Turkey. Corresponding author: Gülistan Bahat, Istanbul University, Istanbul Medical School, Department of Internal Medicine, Division of Geriatrics, Fatih 34093, Istanbul, Turkey, Telephone: +90 2124142000 , Fax: + $902124142248,+90212532$ 42 08, E-Mail Address: gbahatozturk@yahoo.com, ORCID ID: 0000-0001-5343-9795
\end{abstract}

This article is dedicated to the legendary physician and one of the most beloved value of Istanbul Medical Faculty, Professor Cemil Taş̧̧ı̆̆lu, who was actively working and sadly lost at Covid-19 pandemia in Turkey.

At the end of 2019, a new coronavirus, SARS-CoV-2, was identified as the responsible pathogen of a cluster of severe, atypical pneumonia cases from Wuhan city, China. The disease was named as Covid-19 and has spread globally as a pandemic with more than 3 million identified cases and 220,000 death toll over the world in 5 months (1). Since then, some specific virologic and clinical characteristic features related to SARSCoV-2 and Covid-19 have been reported.

First, SARS-CoV-2 is a respiratory pathogen sharing significant similarity with the SARS-CoV that caused an epidemic in 2002-2004 originated in China. It enters the host cells via the ACE2 receptor as does the $\operatorname{SARS}-\mathrm{CoV}(2,3)$. The severity of the disease, i.e. the viral load and lung injury, is positively correlated with the higher angiotensin (Ang) II levels (4). These reports have pointed out the significant role of renin angiotensin system (RAS) at the disease pathogenesis.

RAS has been known more than a century and widely studied for its endocrine effects in maintaining blood pressure, fluid homeostasis, and electrolyte balance. It is long known that a balanced function of RAS is fundamental for circulatory homeostasis. Beyond the well-recognized endocrine function with the circulating RAS, later on, several local tissue RASs have been identified with paracrine and autocrine effects including the heart, kidney, vascular endothelium, adipose tissue, adrenals, liver, lung, pancreas, skeletal muscle, gonads, liver, placenta and brain (5-11). A functional RAS has also been discovered in the mitochondria involving Ang II-mediated intracrine signaling (12). The local tissue RASs have been suggested play a key role in the injury/repair response (8) and have regulatory actions on cell growth, proliferation, inflammation, and cytokine production (13). Thereby, our understanding of the RAS evolved from the circulating RAS to several local tissue RASs in addition to the circulating RAS. The local tissue RASs integrate or complement systemic Ang II (14). Of note, local RASs have capacity of functioning both independently from each other and circulatory RAS besides in correlation with systemic RAS components $(6,15)$. They have important physiological effects that are as important as the circulatory RAS and under some conditions even more important than the circulatory RAS (6).

RAS involves several peptides binding to a family of RAS receptors. It exerts its effects with classical and non-classical Received May 3, 2020

Accepted for publication May 20, 2020 699 pathways which have opposing effects (16). RAS begins with the protease, renin, that is synthesized in the juxtaglomerular cells in kidney. Renin acts on its substrate angiotensinogen which is primarily produced in liver with the resultant product angiotensin I (Ang I). Ang I is biologically non-active agent. It is transformed to the primary product of Ang II in the classical pathway or to the primary product of Ang (1-7) in the non-classical pathway which have antagonistic effects to each other (16). Ang II is mainly produced by the action of angiotensin converting enzyme (ACE), to a much lesser extend by chymases (17). On the other hand, Ang (1-7) is produced by three different ways: a) from Ang II by the action of angiotensin converting enzyme 2 (ACE2) b) from Ang (1-9) by the action of ACE and c) from Ang I by the action of neutral endopeptidase (NEP) (16). The functions of RAS are achieved through the balance between these two main functional peptides, the Ang II and the Ang (1-7), as well as the abundance of their receptors; Ang II type 1 and type 2 receptors (AT1 and AT2) and Ang (1-7) Mas1 receptor. AT1R is vasoconstrictor, anti-natriuretic, fibrotic, inflammatory, AT2R is vasodilator, natriuretic, anti-fibrotic, anti-inflammatory and Mas1 receptor is vasodilator, natriuretic, anti-fibrotic, antiinflammatory (6).

Angiotensin II causes arteriolar vasoconstriction, increases systemic blood pressure and reabsorption of sodium and water. It also acts as an inflammatory mediator through a variety of mechanisms including adhesion molecules, reactive oxygen species, nuclear factor-kB, and superoxide (6). It increases cytokines and chemokines and exerts a proinflammatory effect on leukocytes, endothelial cells and vascular smooth muscle cells (18). It also promotes cellular proliferation, therefore, e.g. exerts a mitogenic stimulus for vascular smooth-muscle cells, fibroblasts, glomerular endothelial cells and hepatic stellate cells $(6,18-21)$. The opposing peptide, Ang (1-7), induces systemic and regional vasodilation, diuresis and natriuresis, and exerts antiproliferative and antigrowth effects such as in vascular smooth muscle cells, cardiac myocytes, fibroblasts, glomerular and proximal tubular cells (13).

RAS components are expressed in the lung and, of note, serum angiotensin converting enzyme increases in a number of interstitial lung diseases (8). Considering the physiological effects of Ang II, it is suggested that Ang II could mediate, Published online June 4, 2020, http://dx.doi.org/10.1007/s12603-020-1403-7 


\section{COVID-19 AND RAS IN OLDER ADULTS}

at least in part, the response to lung injury through increase in vascular permeability, vascular tone and fibroblast activity, and by reducing alveolar epithelial cell survival (8). In a number of lung diseases Ang II has been shown to mediate the disease pathology e.g. idiopathic pulmonary fibrosis, acid or meconium aspiration and sepsis $(5,22-24)$. In line with this view, ACE inhibitors and angiotensin II receptor antagonists were reported to attenuate experimental lung injury $(8,24)$ and have been reported to be useful in some pneumonia cases of experimental animal models and in human (25-27). Accordingly, angiotensin converting enzyme inhibitors (ACEIs), angiotensin receptor blockers (ARBs) were suggested to be useful in the treatment of diffuse parenchymal lung disease and pneumonia $(8,25)$.

In lung diseases causing hypoxia, hypoxia itself seems to increase Ang II concentrations (28). ACE is under promoter regulation by hypoxia-inducing factor $1 \alpha$ that upregulates the ACE expression under hypoxic conditions, resulting in an increase in Ang II concentration during the respiratory distress. In the case of SARS-CoV-2, a further involvement of RAS occurs through the fact that SARS-CoV-2 relies on ACE2 protein to enter and infect the cell. Furthermore, the virus itself downregulates ACE2 expression. Therefore, SARS -CoV-2 infection seems to increase unopposed Ang II against Ang (1-7) much more than the other respiratory infections. This can result in the much more exaggerated signs due to the more dominant Ang II pathway in Covid-19.

The most common presenting clinical symptoms of the Covid-19 are reported as fever, fatigue, dry cough, anorexia, myalgias and dyspnea $(29,30)$. Interestingly, loss of smell and taste disturbances have been noted as a presenting symptom in some reports in the course of pandemic $(31,32)$. In line with increasing observations following the anecdotal reports, British otorhinolaryngology and rhinological society suggested anosmia to be included to the symptom criteria to trigger isolation for limiting Covid-19 dissemination (33). In this report, it has been signified that in South Korea, 30\% of patients testing positive have had anosmia as their major presenting symptom in otherwise mild cases (33). In a study including 417 patients with laboratory-confirmed mild-moderate Covid19 infection recruited from 12 European hospitals, olfactory and gustatory dysfunctions were prevalent in about $85 \%$ of the patients and olfactory dysfunction was not associated with rhinorrhea or nasal obstruction (34). In another study focusing on smell and taste disturbances among 262 ambulatory individuals with influenza-like symptoms from US, smell and taste impairment was strongly associated with positive testing and discriminating the Covid-19 infection (31). These symptoms were about $70 \%$ being nearly as common as fever, cough and myalgia (31). Similarly, among 202 consecutive mildly symptomatic confirmed Covid-19 cases at home management from Italy, smell or taste disturbances were as high as $64.4 \%$ and disturbance was severe in $24 \%$ (32). Only about $1 / 3$ of those patients reported blocked nose (32). They were often the first apparent symptom, more frequent in females and in 3\%, it was the only symptom. Data are scarce on hospitalized patients which may be due to the major signs and symptoms of overt disease. To our knowledge, there is only one study that examined taste and smell disturbances in hospitalized patients (35). This study was performed in 59 hospitalized SARS-CoV-2-positive patients form Italy who did not have severe disease as they were not on ventilation support and so that could have been interviewed. Among them, $34 \%$ reported taste or smell disturbances being more common in females and in younger patients (35). Together, these data suggest smell and taste disturbances are important features of the Covid-19 disease. These studies have been performed in patients with milder symptoms mostly in ambulatory setting as the detection of such disturbances rely on the patient's inquiry. Also, these patients are generally reported younger with female predominance which are among factors associated with better prognosis. Another point is, the prevalence of smell and taste disturbances were higher in the studies reported from the outpatients than that reported from in-patients. Considering these factors, while smell and taste problems might have not been identified during the severe course of the disease due to the overwhelming major signs and symptoms, one can question whether they may also be associated with a milder disease course or not.

As outlined above, the pathogenesis and physiopathology of Covid-19 are very closely related with the RAS. We would like to draw attention that the loss of smell and taste are well-known side effects of pharmacological ACE inhibition with the ACE inhibitors $(36,37)$. The pulmonary ACE expression is subject to negative feedback by Ang II, meaning that increased Ang II causes decreased ACE mRNA levels in the lung and decrease in pulmonary ACE activity (38). The ACE inhibition in this context seems as a physiological response to compensate for the increased Ang II levels. Accordingly, there seems to be some ongoing ACE inhibition during the Covid-19 infectious process as the disease is documented to associate with higher Ang II levels in its pathogenesis (39). This physiologically compensatory ACE inhibition may be, at least, partially related to the loss of smell and taste observed in Covid-19 patients (40). It can be argued that if a patient can effectively inhibit ACE during the infection, the disease may go milder, because the Ang II, which is one of the agents postulated to be responsible from more severe Covid-19, would be produced less. This hypothesis is in accordance with the observations that smell and taste disturbances are reported mostly and more prevalent in outpatients with milder symptoms and also have associations with other favorable prognostic factors as female gender and younger age.

The dry cough is also among very well-known effects of pharmacological ACE inhibitors $(41,42)$ and is a very common symptom accompanying the Covid-19 infection. While the infection affects the upper and lower respiratory system and may therefore cause cough by the irritation of cough receptors, one can question whether there is an additional role of 


\section{THE JOURNAL OF NUTRITION, HEALTH \& AGING}

compensatory host ACE inhibitory response in the pathogenesis of dry cough (39).

The fatigue, anorexia and myalgias are also common symptoms of Covid-19 as are they the other systemic viral infections. They are considered as signs of inflammation and observed in inflammatory conditions other than the infections as vasculitis, rheumatological diseases, neoplasia. Looking from the RAS view, the fatigue and myalgia symptoms may also be contributed by the overactivation of the classical RAS pathway against the non-classical pathway. There has been accumulated reports suggesting the role of increased Ang II in muscle pathologies i.e. sarcopenia and cachexia (4346). In animal models, the increase of Ang II levels proved to induce skeletal fiber wasting through enhanced protein degradation and apoptosis as well as decreased protein synthesis (14). In rodents, Ang II infusion leads to skeletal muscle wasting mediated by alterations in insulin-like growth factor-1 signaling, increased apoptosis, enhanced muscle protein breakdown via the ubiquitin-proteasome system, and decreased appetite due to downregulation of orexigenic hypothalamic neuropeptides orexin and neuropeptide Y (45). It inhibits skeletal muscle stem cell proliferation, leading to lowered muscle regenerative capacity (45). Satellite cells in the muscle acts as muscle stem cells to sustain muscle regeneration after injuries and fiber wasting. Ang II/AT1R axis resulted to reduce satellite cell migration, differentiation and growth. Angiotensin II inhibits satellite cell proliferation and prevents skeletal muscle regeneration (47-51). In accordance with these reports, the decrease in counter-regulatory non-classical pathway of RAS, ACE2 deficiency, has been shown to result in early manifestation of muscle weakness with signatures of muscle senescence in mice which has been attenuated by Ang (1-7) infusion (43). Similarly, the genetic deletion or blockade of the Ang (1-7) Mas receptor has been shown to result in diminished muscle strength, increased fibrosis and highly deteriorated muscular architecture in animal models (52). From the therapeutic view, Ang II AT1 receptor blockade has been reported to improve muscle regeneration in myopathic mice model (53) and resulted to protect the pool of satellite cells promoting muscle regeneration and function improvement in mice model (47). In a small study among heart failure patients, both ACEI and ARB enhanced exercise capacity and muscle performance through their effect on myosin heavy chain (54). ACEIs have also been studied with some positive effects against sarcopenia and physical impairment in older adults without heart failure (55) and suggested to have future role in treatment of sarcopenia (56). A remarkable clinical feature of infections caused by SARS-CoV and SAR-CoV-2 is that they cause severe and rapidly progressing acute respiratory syndrome necessitating ventilatory support in some patients. In the setting of Covid-19, the negative skeletal muscle effects and development of acute sarcopenia are very likely considering the increased Ang II from the classical pathway and decreased ACE2/Ang (1-7) from the non-classical pathway. These effects may also be responsible from the higher need of ventilatory support during the disease course since respiration also depends on skeletal muscles which function as pump and upper airway muscles with diaphragm being the main skeletal pump muscle to move air into the lungs (57). This disease related acute sarcopenia may also be related to the worse prognosis of the disease among older adults. The outlined pathophysiological view also suggests us that the survivors of severe Covid-19 infections may be at much more risk for consequences of sarcopenia. This point would have obviously higher impact in the older adults who are already prone to age-related sarcopenia and therefore need to be closely monitored.

Another remarkable feature of Covid-19 infection is that some patients with severe disease have profuse inflammatory response similar to the cytokine storm syndrome, with elevated inflammatory markers (e.g. d-dimer, ferritin..etc.) and proinflammatory cytokines (58). The disease severity in patients is due to not only the viral infection but also the host response (59). Uncontrolled inflammation causes multi-organ damage leading to multi-organ failure (59). The hyperinflammation is considered as secondary hemophagocytic lymphohistiocytosis, it is associated with critical and fatal illness and recommended to be treated to reduce mortality by agents that control or decrease inflammation such as by selective cytokine blockade (e.g. anakinra, tocilizumab), JAK inhibition (58). As outlined above, the overactivation of the classical RAS pathway is associated with exaggerated inflammatory response mediated by Ang II through the AT1 receptor system and seems to have role in this pathology. Angiotensin II levels in Covid-19 patients on admission are reported twice the normal levels (4). Pulmonary vascular inflammation leads to endothelial surface-bound ACE to be released into the interstitium called as ACE "shedding" resulting in increase in plasma ACE activity $(60,61)$. This phenomenon also produces a sharp increase in local Ang II $(60,62)$. Angiotensin II causes endothelial activation, proinflammatory cytokine release and platelet activation that further enhance a pro-thrombotic milieu (62). Angiotensin II also has potent chemotactic effects that may accelerate lymphocyte recruitment and suppression. As outlined above Ang II has been implicated to mediate a number of lung diseases. Presence of the exaggerated immune response that is specifically found in Covid-19 and SARS but not in other Ang II mediated lung diseases may be due to the further impairment of Ang II to Ang (1-7) balance that can be attributed to consumption and decreased expression of ACE2 specific to these disease pathologies. The adverse effects of increased Ang II pathway would be more hazardous in the older adults also regarding the hyper-inflammation aspect. Ageing is associated with increase in inflammatory markers and dysregulation of the system, a situation called inflammaging (63). Hyperinflammation has been reported more common in the older patients with Covid-19 and this may be related with already dysregulated immune system in the older adults, a 


\section{COVID-19 AND RAS IN OLDER ADULTS}

factor that may underline the increased risk of mortality in the older adults (63). On the other hand, as clinicians dealing with older adults, we should consider that peripheral inflammation caused by Covid-19 may have long-term consequences in those that recover, leading to chronic medical conditions (64) such as dementia and neurodegenerative diseases, sarcopenia for which older adults are already at higher risk.

After identification of ACE2 as the gate for SARS-CoV-2 entry, use of ACEI/ARB has become controversial in the setting of Covid-19. From infectivity point of view, the factors that increase ACE2 expression have potential to increase virulence and infection risk by the virus (65-67). It has been concerned because, while inconsistently, ACEIs and ARBs have been reported to increase the expression of ACE2 receptor in animal and limited human studies (68-70). The crucial role of ACE2 has been demonstrated in a mice model of SARS-CoV infection reporting little or no viral replication in ACE2 deficient mice (27). On the other hand, as outlined above, regarding the disease pathophysiology mediated by increased and unopposed Ang II, the therapies directed to increase ACE2 expression (ACEIs, ARBs), decrease Ang II production (ACEIs) or its effects (ARBs) may well have role to counteract the disease pathophysiology $(27,65,66,71)$ by balancing the imbalanced Ang II/Ang (1-7) axis in the favor of Ang (1-7) and thereby prevent acute lung injury and risk of acute respiratory distress syndrome. Therefore, evaluation of safety and possible beneficial effect of antihypertensive therapy with RAS blockade has been very much needed in the setting of Covid-19 pandemia (65). Some evidence on this regard has come with four very recently and consecutively published articles with a relatively high participant number (72-75). In a retrospective, multicenter study including 1128 adult patients with hypertension diagnosed with Covid-19 in Hubei, China, inpatient use of ACEI/ARB was associated with lower risk of 28-day all-cause mortality compared with ACEI/ARB non-users after adjusting for age, gender, comorbidities, and in-hospital medications (72). In another observational, retrospective multicentric study including 8910 patients from 169 hospitals in Asia, Europe and North America, use of ACEI/ARB was not associated with increased risk of in-hospital death after adjustment with age, race, coexisting conditions (coronary artery disease, congestive heart failure, cardiac arrhythmia, diabetes mellitus, chronic obstructive pulmonary disease, current smoking, former smoking, hypertension, immunocompromised state, hyperlipidemia), country of origin, and other medications (beta-blockers, antiplatelet agents, statins, insulin, and oral hypoglycemic agents). Notably, the use of ACE inhibitors were associated with a better chance of survival to hospital discharge while no association found for the use of ARBs (73). Another study came from Lombardy, Italy which was a populationbased case-control study including 6272 case patients with SARS-CoV-2 and matched 30,759 controls according to sex, age, and municipality of residence (74). While the use of ACEIs and ARBs was more common among case patients, it did not show any association with Covid-19 among case patients overall or among patients who had a severe or fatal course of the disease (74). Lastly, Reynolds et al. conducted a study based on data from the electronic health records of 12,594 patients in the New York University among whom 5894 were tested positive and 1002 had severe disease (75). They assessed the relation between previous treatment with antihypertensive drugs including ACEIs and ARBs and the likelihood of a positive or negative result on Covid-19 testing as well as the likelihood of severe illness. Again, there was not any association between ACEIs/ARBs and an increased likelihood of a positive test nor with an increase in the risk of severe illness (75). The two later study, therefore, suggested that the risk of infection was also not increased among ACEI/ ARB users $(74,75)$. Some other smaller studies published priorly from China also reported that ACEIs/ARBs were not associated with the severity or mortality of Covid-19 $(76,77)$. All these data suggest that ACEI or ARB use is not associated with the risk of SARS-CoV-2 infection, more severe disease course or the risk of in-hospital death in Covid-19 patients. It should be considered that these studies are observational data and still one or more randomized trials are needed to answer definitively whether ACEIs/ARBs pose a harm to patients with Covid-19 (78). However, considered all together, these studies suggest that an increase in infection risk or severity, or mortality related to the Covid-19 is unlikely with use of ACEIs/ ARBs. In older adults, the prevalence of hypertension, diabetes, cardiovascular diseases and heart failure is higher than the younger counterparts, as are the risks for acquiring infection, severe infection and infection-related mortality. Therefore, possible concerns and beneficial effects related with use of ACEIs/ARBs are of great interest and these study results have shed some light for the concerns of clinicians dealing with older adults.

\section{Disclosure: The author declares there is no conflict of interest.}

Acknowledgement: I would like to express our gratitudes and thanks to Professor Cemil Taşçığlu because meeting, studying, living with him and learning from him was an exceptional honor. His legendary clinical approaches, teachings, kindness and human love will guide and live with us as one of our most precious legacies. He will be missed too much as an exceptional friend, an exceptional clinician and an exceptional teacher.

\section{References}

1. https://covid19.who.int/. (accessed on May 2, 2020)

2. Li W, Moore MJ, Vasilieva N, Sui J, Wong SK, Berne MA, et al. Angiotensinconverting enzyme 2 is a functional receptor for the SARS coronavirus. Nature. 2003;426(6965):450-4.

3. Hoffmann M, Kleine-Weber H, Schroeder S, Krüger N, Herrler T, Erichsen S, et al. SARS-CoV-2 Cell Entry Depends on ACE2 and TMPRSS2 and Is Blocked by a Clinically Proven Protease Inhibitor. Cell. 2020;181(2):271-80.e8.

4. Liu Y, Yang Y, Zhang C, Huang F, Wang F, Yuan J, et al. Clinical and biochemical indexes from 2019-nCoV infected patients linked to viral loads and lung injury. Sci China Life Sci. 2020;63(3):364-74.

5. Abdul-Hafez A, Mohamed T, Omar H, Shemis M, Uhal BD. The renin angiotensin system in liver and lung: impact and therapeutic potential in organ fibrosis. J Lung Pulm Respir Res. 2018;5(1)

6. NDL F. Overview of the renin-angiotensin system. UpToDate (last accessed on May, 2020).

7. Dzau VJ. Tissue renin-angiotensin system in myocardial hypertrophy and failure. Arch 


\section{THE JOURNAL OF NUTRITION, HEALTH \& AGING}

Intern Med. 1993:153(8):937-42.

8. Marshall RP. The pulmonary renin-angiotensin system. Curr Pharm Des 2003;9(9):715-22.

9. Cabello-Verrugio C, Morales MG, Rivera JC, Cabrera D, Simon F. Renin-angiotensin system: an old player with novel functions in skeletal muscle. Med Res Rev. 2015;35(3):437-63.

10. Grace JA, Herath CB, Mak KY, Burrell LM, Angus PW. Update on new aspects of the renin-angiotensin system in liver disease: clinical implications and new therapeutic options. Clin Sci (Lond). 2012;123(4):225-39.

11. Goossens GH. The renin-angiotensin system in the pathophysiology of type 2 diabetes. Obes Facts. 2012;5(4):611-24.

12. Abadir PM, Foster DB, Crow M, Cooke CA, Rucker JJ, Jain A, et al. Identification and characterization of a functional mitochondrial angiotensin system. Proc Natl Acad Sci U S A. 2011;108(36):14849-54.

13. Varagic J, Ahmad S, Nagata S, Ferrario CM. ACE2: angiotensin II/angiotensin-(1-7) balance in cardiac and renal injury. Curr Hypertens Rep. 2014;16(3):420.

14. Sartiani L, Spinelli V, Laurino A, Blescia S, Raimondi L, Cerbai E, et al Pharmacological perspectives in sarcopenia: a potential role for renin-angiotensin system blockers? Clin Cases Miner Bone Metab. 2015;12(2):135-8.

15. Froogh G, Pinto JT, Le Y, Kandhi S, Aleligne Y, Huang A, et al. Chymase-dependent production of angiotensin II: an old enzyme in old hearts. Am J Physiol Heart Circ Physiol. 2017;312(2):H223-h31.

16. Powers SK, Morton AB, Hyatt H, Hinkley MJ. The Renin-Angiotensin System and Skeletal Muscle. Exerc Sport Sci Rev. 2018;46(4):205-14.

17. Li M, Liu K, Michalicek J, Angus JA, Hunt JE, Dell'Italia LJ, et al. Involvement of chymase-mediated angiotensin II generation in blood pressure regulation. J Clin Invest. 2004;114(1):112-20.

18. Dandona P, Dhindsa S, Ghanim H, Chaudhuri A. Angiotensin II and inflammation: the effect of angiotensin-converting enzyme inhibition and angiotensin II receptor blockade. J Hum Hypertens. 2007;21(1):20-7.

19. Marshall RP, McAnulty RJ, Laurent GJ. Angiotensin II is mitogenic for human lung fibroblasts via activation of the type 1 receptor. Am J Respir Crit Care Med. 2000;161(6):1999-2004

20. Wolf G, Ziyadeh FN, Zahner G, Stahl RA. Angiotensin II is mitogenic for cultured rat glomerular endothelial cells. Hypertension. 1996;27(4):897-905.

21. Bataller R, Ginès P, Nicolás JM, Görbig MN, Garcia-Ramallo E, Gasull X, et al. Angiotensin II induces contraction and proliferation of human hepatic stellate cells. Gastroenterology. 2000;118(6):1149-56.

22. Uhal BD, Li X, Piasecki CC, Molina-Molina M. Angiotensin signalling in pulmonary fibrosis. Int J Biochem Cell Biol. 2012;44(3):465-8.

23. Uhal BD, Abdul-Hafez A. Angiotensin II in apoptotic lung injury: potential role in meconium aspiration syndrome. J Perinatol. 2008;28 Suppl 3:S108-12.

24. Imai Y, Kuba K, Rao S, Huan Y, Guo F, Guan B, et al. Angiotensin-converting enzyme 2 protects from severe acute lung failure. Nature. 2005;436(7047):112-6.

25. Mortensen EM, Nakashima B, Cornell J, Copeland LA, Pugh MJ, Anzueto A, et al Population-based study of statins, angiotensin II receptor blockers, and angiotensinconverting enzyme inhibitors on pneumonia-related outcomes. Clin Infect Dis 2012;55(11):1466-73

26. Fedson DS, Jacobson JR, Rordam OM, Opal SM. Treating the Host Response to Ebola Virus Disease with Generic Statins and Angiotensin Receptor Blockers. mBio. 2015;6(3):e00716.

27. Kuba K, Imai Y, Rao S, Gao H, Guo F, Guan B, et al. A crucial role of angiotensin converting enzyme 2 (ACE2) in SARS coronavirus-induced lung injury. Nat Med 2005;11(8):875-9.

28. Wong M. Angiotensin Converting Enzymes. Handbook of Hormones Comparative Endocrinology for Basic and Clinical Research. 2016:263-5, e29D-1-e29D-4.

29. Wang D, Hu B, Hu C, Zhu F, Liu X, Zhang J, et al. Clinical Characteristics of 138 Hospitalized Patients With 2019 Novel Coronavirus-Infected Pneumonia in Wuhan, China. JAMA. 2020;323(11):1061-9.

30. Goyal P, Choi JJ, Pinheiro LC, Schenck EJ, Chen R, Jabri A, et al. Clinica Characteristics of Covid-19 in New York City. N Engl J Med. 2020.

31. Yan C, Faraji, F., Prajapati DP., Boone, CE., DeConde, AS. . Association of Chemosensory Dysfunction and Covid-19 in Patients Presenting with Influenzalike Symptoms. International Forum of Allergy and Rhinology. 2020:https://www researchgate.net/deref/https\%3A\%2F\%Fdoi.org\%F10.1111\%2Falr.22579 (accesed on May 2, 2020).

32. Spinato G, Fabbris C, Polesel J, Cazzador D, Borsetto D, Hopkins C, et al. Alterations in Smell or Taste in Mildly Symptomatic Outpatients With SARS-CoV-2 Infection. JAMA. 2020.

33. https://www.entuk.org/loss-sense-smell-marker-covid-19-infection. (accessed on May 2,2020).

34. Lechien JR, Chiesa-Estomba CM, De Siati DR, Horoi M, Le Bon SD, Rodriguez A, et al. Olfactory and gustatory dysfunctions as a clinical presentation of mild-to-moderate forms of the coronavirus disease (COVID-19): a multicenter European study. Eur Arch Otorhinolaryngol. 2020:1-11.

35. Giacomelli A, Pezzati L, Conti F, Bernacchia D, Siano M, Oreni L, et al. Self-reported olfactory and taste disorders in SARS-CoV-2 patients: a cross-sectional study. Clin Infect Dis. 2020.

36. Doty RL, Philip S, Reddy K, Kerr KL. Influences of antihypertensive and antihyperlipidemic drugs on the senses of taste and smell: a review. J Hypertens. 2003;21(10):1805-13.

37. Bromley SM. Smell and taste disorders: a primary care approach. Am Fam Physician. 2000;61(2):427-36, 38

38. Schunkert H, Ingelfinger JR, Hirsch AT, Pinto Y, Remme WJ, Jacob H, et al Feedback regulation of angiotensin converting enzyme activity and mRNA levels by angiotensin II. Circ Res. 1993;72(2):312-8.

39. Bahat $\mathrm{G}$. Angiotensin converting enzyme (ACE) inhibition may have a role in the symptoms and progression of COVID-19 infection. BMJ.https://www.bmj.com/ content/368/bmj.m406/rr-23 (accessed on May 2, 2020).

40. Bahat G. Loss of smell and taste in the course of COVID-19 infection may be related to angiotensin converting enzyme (ACE) inhibition. BMJ.https://www.bmj.com/ content/368/bmj.m406/rr-27 (accessed on May 2, 2020).

41. Israili ZH, Hall WD. Cough and angioneurotic edema associated with angiotensinconverting enzyme inhibitor therapy. A review of the literature and pathophysiology. Ann Intern Med. 1992;117(3):234-42.

42. Dicpinigaitis PV. Angiotensin-Converting Enzyme Inhibitor-Induced Cough: ACCP Evidence-Based Clinical Practice Guidelines. CHEST. 2006;129(1):169S-73S

43. Takeshita H, Yamamoto K, Nozato S, Takeda M, Fukada SI, Inagaki T, et al. Angiotensin-converting enzyme 2 deficiency accelerates and angiotensin 1-7 restores age-related muscle weakness in mice. J Cachexia Sarcopenia Muscle. 2018;9(5):97586

44. Rolland Y, Czerwinski S, Abellan Van Kan G, Morley JE, Cesari M, Onder G, et al. Sarcopenia: its assessment, etiology, pathogenesis, consequences and future perspectives. J Nutr Health Aging. 2008;12(7):433-50.

45. Delafontaine P, Yoshida T. THE RENIN-ANGIOTENSIN SYSTEM AND THE BIOLOGY OF SKELETAL MUSCLE: MECHANISMS OF MUSCLE WASTING IN CHRONIC DISEASE STATES. Trans Am Clin Climatol Assoc. 2016;127:245-58.

46. Anker SD, Negassa A, Coats AJ, Afzal R, Poole-Wilson PA, Cohn JN, et al. Prognostic importance of weight loss in chronic heart failure and the effect of treatment with angiotensin-converting-enzyme inhibitors: an observational study. Lancet. 2003;361(9363):1077-83.

47. Yoshida T, Galvez S, Tiwari S, Rezk BM, Semprun-Prieto L, Higashi Y, et al Angiotensin II inhibits satellite cell proliferation and prevents skeletal muscle regeneration. J Biol Chem. 2013;288(33):23823-32.

48. Yoshida T, Huq TS, Delafontaine P. Angiotensin type 2 receptor signaling in satellite cells potentiates skeletal muscle regeneration. J Biol Chem. 2014;289(38):26239-48.

49. Johnston AP, Baker J, Bellamy LM, McKay BR, De Lisio M, Parise G. Regulation of muscle satellite cell activation and chemotaxis by angiotensin II. PLoS One. 2010;5(12):e15212.

50. Dalla Libera L, Ravara B, Angelini A, Rossini K, Sandri M, Thiene G, et al. Beneficial effects on skeletal muscle of the angiotensin II type 1 receptor blocker irbesartan in experimental heart failure. Circulation. 2001;103(17):2195-200.

51. Solomon AM, Bouloux PM. Modifying muscle mass - the endocrine perspective. J Endocrinol. 2006;191(2):349-60

52. Acuña MJ, Pessina P, Olguin H, Cabrera D, Vio CP, Bader M, et al. Restoration of muscle strength in dystrophic muscle by angiotensin-1-7 through inhibition of TGF- $\beta$ signalling. Hum Mol Genet. 2014;23(5):1237-49

53. Cohn RD, van Erp C, Habashi JP, Soleimani AA, Klein EC, Lisi MT, et al. Angiotensin II type 1 receptor blockade attenuates TGF-beta-induced failure of muscle regeneration in multiple myopathic states. Nat Med. 2007;13(2):204-10.

54. Vescovo G, Dalla Libera L, Serafini F, Leprotti C, Facchin L, Volterrani M, et al Improved exercise tolerance after losartan and enalapril in heart failure: correlation with changes in skeletal muscle myosin heavy chain composition. Circulation. 1998;98(17):1742-9.

55. Sumukadas D, Witham MD, Struthers AD, McMurdo ME. Effect of perindopril on physical function in elderly people with functional impairment: a randomized controlled trial. Cmaj. 2007;177(8):867-74.

56. Morley JE. Treatment of sarcopenia: the road to the future. J Cachexia Sarcopenia Muscle. 2018;9(7):1196-9.

57. Gransee HM, Mantilla CB, Sieck GC. Respiratory muscle plasticity. Compr Physiol. 2012;2(2):1441-62.

58. Mehta P, McAuley DF, Brown M, Sanchez E, Tattersall RS, Manson JJ. COVID19: consider cytokine storm syndromes and immunosuppression. Lancet. 2020;395(10229):1033-4.

59. Tay MZ, Poh CM, Rénia L, MacAry PA, Ng LFP. The trinity of COVID-19: immunity, inflammation and intervention. Nat Rev Immunol. 2020. 


\section{COVID-19 AND RAS IN OLDER ADULTS}

60. Nukiwa T, Matsuoka R, Takagi H, Ishii Y, Arai T, Kira S. Responses of serum and lung angiotensin-converting enzyme activities in the early phase of pulmonary damage induced by oleic acid in dogs. Am Rev Respir Dis. 1982;126(6):1080-6.

61. Hermanns MI, Müller AM, Tsokos M, Kirkpatrick CJ. LPS-induced effects on angiotensin I-converting enzyme expression and shedding in human pulmonary microvascular endothelial cells. In Vitro Cell Dev Biol Anim. 2014;50(4):287-95.

62. Leisman DE, Deutschman CS, Legrand M. Facing COVID-19 in the ICU: vascular dysfunction, thrombosis, and dysregulated inflammation. Intensive Care Medicine. 2020 .

63. Saghazadeh A, Rezaei N. Immune-epidemiological parameters of the novel coronavirus - a perspective. Expert Rev Clin Immunol. 2020;0(0):1-6.

64. Butler MJ, Barrientos RM. The impact of nutrition on COVID-19 susceptibility and long-term consequences. Brain Behav Immun. 2020.

65. Messerli FH, Siontis GCM, Rexhaj E. COVID-19 and Renin Angiotensin Blockers: Current Evidence and Recommendations. Circulation. 2020

66. Bahat G. To use or not to use Renin Angiotensin Aldosterone System blocking agents in the setting of COVID-19 pandemic. BMJ.https://www.bmj.com/content/368/bmj. m810/rr-40 (last accessed May 2, 2020).

67. D'Ardes D, Boccatonda A, Rossi I, Guagnano MT, Santilli F, Cipollone F, et al. COVID-19 and RAS: Unravelling an Unclear Relationship. Int J Mol Sci. 2020;21(8).

68. Igase M, Kohara K, Nagai T, Miki T, Ferrario CM. Increased expression of angiotensin converting enzyme 2 in conjunction with reduction of neointima by angiotensin II type 1 receptor blockade. Hypertens Res. 2008;31(3):553-9.

69. Ferrario CM, Jessup J, Chappell MC, Averill DB, Brosnihan KB, Tallant EA, et al. Effect of angiotensin-converting enzyme inhibition and angiotensin II receptor blockers on cardiac angiotensin-converting enzyme 2. Circulation. 2005;111(20):260510 .

70. Vaduganathan M, Vardeny O, Michel T, McMurray JJV, Pfeffer MA, Solomon SD Renin-Angiotensin-Aldosterone System Inhibitors in Patients with Covid-19. N Engl J Med. 2020;382(17):1653-9.
71. Brandon M. COVID-19 induced Renin-Angiotensin System (RAS) imbalance may drive acute lung injury: the evidence and therapeutic options. BMJ.www.bmj.com/ content/368/bmj.m406/rr-19 (accessed on May 2, 2020).

72. Zhang P, Zhu L, Cai J, Lei F, Qin JJ, Xie J, et al. Association of Inpatient Use of Angiotensin Converting Enzyme Inhibitors and Angiotensin II Receptor Blockers with Mortality Among Patients With Hypertension Hospitalized With COVID-19. Circ Res 2020

73. Mehra MR, Desai SS, Kuy S, Henry TD, Patel AN. Cardiovascular Disease, Drug Therapy, and Mortality in Covid-19. New England Journal of Medicine. 2020.

74. Mancia G, Rea F, Ludergnani M, Apolone G, Corrao G. Renin-AngiotensinAldosterone System Blockers and the Risk of Covid-19. New England Journal of Medicine. 2020

75. Reynolds HR, Adhikari S, Pulgarin C, Troxel AB, Iturrate E, Johnson SB, et al Renin-Angiotensin-Aldosterone System Inhibitors and Risk of Covid-19. New England Journal of Medicine. 2020.

76. Meng J, Xiao G, Zhang J, He X, Ou M, Bi J, et al. Renin-angiotensin system inhibitors improve the clinical outcomes of COVID-19 patients with hypertension. Emerg Microbes Infect. 2020;9(1):757-60

77. Li J, Wang X, Chen J, Zhang H, Deng A. Association of Renin-Angiotensin System Inhibitors With Severity or Risk of Death in Patients With Hypertension Hospitalized for Coronavirus Disease 2019 (COVID-19) Infection in Wuhan, China. JAMA Cardiol. 2020.

78. Jarcho JA, Ingelfinger JR, Hamel MB, D'Agostino RB, Harrington DP. Inhibitors of the Renin-Angiotensin-Aldosterone System and Covid-19. New England Journal of Medicine. 2020. 